\title{
Preventive effect of taurine on experimental type II diabetic nephropathy
}

\author{
Shumei Lin ${ }^{\dagger}$, Jiancheng Yang, Gaofeng Wu, Mei Liu, Xinhong Luan, Qiufeng Lv, He Zhao, Jianmin Hu* \\ From $17^{\text {th }}$ International Meeting of Taurine \\ Fort Lauderdale, FL, USA. 14-19 December 2009
}

\begin{abstract}
Background: It has been verified that taurine has some preventive effects on diabetes and its complications when used alone or together with other drugs, but there are few reports about taurine on the prevention of diabetic nephropathy, the mechanisms of which are still unknown.

Methods: Taurine was administered to type II diabetic rats induced by high fat high sugar diet combined with STZ injection. The preventive effect of taurine on diabetic nephropathy was investigated by detecting blood glucose, lipid metabolism, kidney function and glomerular basement membrane metabolism.

Results: Taurine could lower blood glucose, TG, TC, BUN, Scr, NAG, U-PRO, the expression of laminin B1( LBN1) mRNA, and increase HDL-C of diabetic rats.

Conclusions: The results indicated that taurine could prevent the occurrence and development of diabetic nephropathy by decreasing blood glucose, improving lipid metabolism, glomerular basement membrane metabolism, and kidney function.
\end{abstract}

\section{Introduction}

Diabetic nephropathy (DN) whose incidence is up to $47.66 \%$ is the most common and difficult diabetic microvascular complication to treat and has become the first cause of end-stage renal disease [1-3]. It is reported that about $43 \%$ of the chronic renal failure (CRF) patients on dialysis are $\mathrm{DN}, 60 \%$ case fatality of diabetes mellitus (DM) patients are DN, DM patients who died of renal failure are 17 times more than non-DM patients [4]. Therefore, prevention of the occurrence and the development of DN has become a very urgent issue.

Taurine, a sulfur-containing $\beta$-amino acid with a wide range of biological effects, is the most abundant free intracellular amino acid presents in many tissues of humans and animals [5]. Researches have demonstrated that taurine has some preventive and curative effects on DN. H.Trachtman (1995) found that 1\% taurine

\footnotetext{
* Correspondence: hujianmin59@163.com

† Contributed equally

College of Animal Science \& Veterinary Medicine, Shenyang Agricultural

University, Shenyang, 110866, P.R. China

Full list of author information is available at the end of the article
}

supplementation in drinking water for 52 weeks could reduce total proteinuria (U-PRO) and albuminuria by nearly $50 \%$. This treatment also prevented glomerular hypertrophy, diminished glomerulosclerosis and tubulointerstitial fibrosis in diabetic animals [6]. It was reported by A.Erden (2000) that taurine could reduce gentamicin induced increases in serum creatinine (Scr), $24 \mathrm{~h}$ urine volume, serum urea nitrogen (BUN) and tissue lactate and TBARS levels [7]. S.Higo (2008) reported that taurine administration significantly suppressed further increase in urinary protein excretion in diabetic rats [8]. Four weeks after intravenous injection of 50 $\mathrm{mg} / \mathrm{kg}$ streptozotocin (STZ), diabetic rats exhibited 6.1 fold increase in urinary protein excretion, taurine supplement by $1 \%$ in drinking water prevented increases proteinuria [9].The reports mentioned above indicated that the previous study about taurine on $\mathrm{DN}$ were all concerned with typelDN induced by STZ. There were no reports about preventive effects of taurine on type II DN by artificial induction. In diabetes mellitus, expansion of the glomerular mesangium correlates with the clinical features of diabetic kidney disease. The increase 
in mesangial matrices is due primarily to the accumulation of normal matrix proteins, including collagens type IV and type V, laminin (LN), and fibronectin [10]. As a main protein composition in glomerular basement membrane, LN could reflect the dynamic state of extracellular matrix (ECM) synthesis. So LN was considered as a main index for renal injury, as well as for the development of DN. There were no reports about the effect of taurine on LN.

In this study, the preventive effect and its mechanism of taurine on DN would be investigated, in order to provide a theoretical basis for clinical application of taurine.

\section{Methods}

\section{Experimental animals and treatments}

Six-week-old male Wistar rats weighing 140-180g were maintained under a controlled condition of light (12h of light, $12 \mathrm{~h}$ of dark) and temperature $\left(23 \pm 2^{\circ} \mathrm{C}\right)$, and were given free access to food (commercial standard rat chow) and water.

One hundred and ten male Wistar rats weighing 140$180 \mathrm{~g}$ were randomly divided into two groups: normal control group (A group, 20 rats) and model group (M group, 90 rats). Rats in $\mathrm{M}$ group were fed with a high sugar, high fat diet for one month to induce insulin resistance (IR), and then injected with STZ $(25 \mathrm{mg} / \mathrm{kg})$ once per week for two weeks. Rats in A group were injected with citric acid-citrate sodium buffer solution. Rats in $M$ group were fed with a high sugar, high fat diet for two months after STZ injection. Then fasting blood glucose, random blood glucose and fasting insulin were detected seven days after the second STZ injection. DM rats in $M$ group were divided into four groups randomly (18 rats in each group): spontaneous recovery group (B), high concentration of taurine group (C), medium concentration of taurine group (D) and low concentration of taurine group (E). Rats in B, C, D and E groups were administered with $0 \mathrm{mg} / \mathrm{kg}, 3.4 \mathrm{mg} / \mathrm{kg}$, $2.6 \mathrm{mg} / \mathrm{kg}$, and $2.1 \mathrm{mg} / \mathrm{kg} 70 \%$ taurine suspension respectively. Rats in A and B groups received the same treatment. At the end of the 6th and the 10th weeks, five rats were selected from each group, blood was collected from the jugular vein, then BUN, Scr, $\beta-\mathrm{N}$-acetyl-glucosaminidase (NAG), triglyceride (TG), total cholesterol (TC) and high-density lipoprotein cholesterol (HDL-C) were detected. Twenty-four $\mathrm{h}$ urine samples were collected and U-PRO was detected. Renal basement membrane adhesion protein expression was detected by way of in-situ hybridization.

\section{Chemicals}

Blood glucose meters and blood glucose test strips with lot number were purchased from U.S. Roche. STZ was purchased from Sigma Chemical Company. Sugar, cholesterol, and bile salt were purchased from Shenyang Chemical Reagent Co., Ltd. Taurine was purchased from Beijing Capital Commercial Source Co., Ltd. Insulin RIA kit was purchased from China Institute of Atomic Energy Research Institute of Isotopes. BUN, Scr, NAG, U-PRO, TG, TC, HDL-C kits were purchased from Nanjing Jiancheng Bioengineering Institute. Diethyl pyrocarbonate (DEPC), Paraformaldehyde, Special coverslip in situ hybridization and in situ hybridization detection kits were purchased from Wuhan Boster Biological Engineering Co., Ltd.

\section{Experimental diets}

Normal diet was purchased from Yuhong District test animal feed factory (Shenyang), the nutrition ingredient of which is in accordance with the nutritional standards. High-fat high-sugar feed was purchased from Yuhong District test animal feed factory (Shenyang) which contains $15 \%$ lard, $25 \%$ sucrose, $2.5 \%$ cholesterol, $1 \%$ bile salts and $56.5 \%$ normal feed.

\section{Judgments of model}

Determination of fasting blood glucose: After an overnight (10-12 h) fast, during which only water was permitted. Blood was collected from the tail. The first drop of blood was wiped off, and the second drop of blood was used to determine the blood glucose using blood glucose test strips.

Determination of random blood glucose: without fasting, methods were the same as mentioned above. Determination of insulin levels: $200-300 \mu \mathrm{L}$ whole blood was collected from the tails. After standing at room temperature for $4 \mathrm{~h}$, serum was separated by centrifuging at $1500 \mathrm{rpm}$ for $15 \mathrm{~min}$ at $4^{\circ} \mathrm{C}$. INS was determined using an insulin RIA kit.

The establishment of animal models of T2DM must meet the following two conditions:

(1) ISI $=$ Ln $[1 /$ (fasting glucose $\times$ serum insulin level)] $\leq$ the mean value of normal animals;

(2) the mean value of random blood glucose levels in normal rats +2 standard deviation $\leq$ the random blood glucose of model group.

\section{Standardization of insulin resistance}

HOMA-IR $=($ FBGxFINS) / 22.5 was used to evaluate the degree of insulin resistance, while ISI=1 / (FBGxFINS) was used to demonstrate the insulin sensitivity. Calculate the natural logarithm of HOMA-IR and ISI [11].

\section{Biochemical analysis}

Blood samples were collected from the jugular vein of 5 rats randomly selected from each group at the end of the 6 th and the 10th weeks. After standing at room temperature for $4 \mathrm{~h}$, serum was separated by centrifuging 
at $1500 \mathrm{rpm}$ for $15 \mathrm{~min}$ at $4{ }^{\circ} \mathrm{C}$, stored at $-20{ }^{\circ} \mathrm{C}$. BUN, Scr, NAG, TG, TC, HDL-C were determined by colorimetry using kits. U-PRO was detected using urine collected from a metabolic cage for 24 hours.

\section{Kidney in-situ hybridization}

The paraffin section of the rat's kidney was dewaxed. Endogenous peroxidase was deactivated after being treated with 3\% hydrogen peroxide at room temperature for $10 \mathrm{~min}$. Then the section was digested with pepsin at $37^{\circ} \mathrm{C}$ for $20 \mathrm{~min}$ in order to expose the mRNA nucleic acid fragment. Dropped $20 \mu$ l oligonucleotide probe hybridization solution containing Cardiox was added on each slice over night. Then confining liquid, biotinylation rat anti biotinylation antibody and SABC were added to each section. They were then colored with $D A B$, redyed with hematoxylin, transparented with xylene, and mounted with neutral gum. The assessment criteria of positive cells: the cell is positive if there are brown granules in the cytoplasm observed under optical microscope. Negative control of in situ hybridization: $0.5 \mathrm{~mol} / \mathrm{LPBS}$ was used instead of nucleotide probe hybridization solution, repeat the above steps. The expression value was measured using the average relative gray scale.

\section{Statistical analysis}

Data were presented as the mean \pm SD and significant differences were determined by Duncan's multiple range tests using SPSS 16.0 statistical analysis software. P values less than 0.05 were considered as significant, $P$ values less than 0.01 were considered as extremely significant.

\section{Results}

\section{Percentage of model establishment}

Random blood glucose and ISI of groups A and M were shown in Table 1. The result meets the requirements of the T2DM rat model. 74 rat models were established, the percentage was $82 \%$.

Insulin resistance analysis

FBG, FINS, ISI and HOMA-IR of groups $\mathrm{A}$ and $\mathrm{M}$ were shown in Table 2.The FBG and HOMA-IR of Group M

Table 1 Results of the random glucose level and ISI of Group $C$ and $M$

\begin{tabular}{lccc}
\hline Group & amount & $\begin{array}{c}\text { random blood glucose (mmol/ } \\
\text { L) }\end{array}$ & ISI \\
\hline Model group & 74 & $15.03 \pm 9.53$ & -5.13 \\
& & & \pm 0.69 \\
Control & 20 & $6.3 \pm 0.46$ & -4.32 \\
group & & & \pm 0.46 \\
\hline
\end{tabular}

Results are presented as mean \pm SD C: control group, M: model group

Table 1 The results of the level of random glucose and ISI of Group A and M
Table 2 Results of the insulin resistance of Group C and $M$

\begin{tabular}{lccccc}
\hline Group & amount & $\begin{array}{c}\text { FBG (mmol/ } \\
\text { L) }\end{array}$ & FINS(IU/L) & ISI & $\begin{array}{c}\text { HOMA- } \\
\text { IR }\end{array}$ \\
\hline Model & 74 & $5.43 \pm 0.75^{* *}$ & 34.59 & -5.13 & 2.04 \\
group & & & $\pm 13.86^{*}$ & $\pm 0.69^{*}$ & $\pm 0.40^{* *}$ \\
Control & 20 & $4.02 \pm 0.29$ & $21.45 \pm 5.33$ & -4.32 & $1.36 \pm 0.26$ \\
group & & & & \pm 0.46 &
\end{tabular}

Results are presented as mean \pm SD C: control group, M: model group

Table 2 The results of the insulin resistence of Group $A$ and $M$

${ }^{*} \mathrm{P} \otimes 0.05{ }^{* *} \mathrm{P} \otimes 0.01$

was significantly higher $(\mathrm{P}<0.01)$ than the normal rats at the seventh day after STZ injection. The FINS and ISI of Group M was significantly higher $(P<0.05)$ than the normal rats. The results indicated that 74 rats in the model group all exhibited insulin resistance, which means that the rats were type II diabetes models.

\section{Blood glucose analysis}

Figure 1 showed that the blood glucose level of spontaneous recovery group was significantly higher $(P<0.01)$ than the normal rats at the end of the 6th and the 10th weeks. The blood glucose level of the taurine- preventive groups was significantly lower than that of the spontaneous recovery group, and particularly the highconcentration of taurine group had no significant differences compared with the control group.

\section{Analysis of lipid metabolism indexes}

As shown in Fig. 2, serum concentrations of HDL-C, TG and TC in the spontaneous recovery group were significantly affected compared with the control group $(\mathrm{P}<0.01$ or $\mathrm{P}<0.05)$, among which, the concentration of HDL-C was significantly decreased, and the concentrations of TG and TC were significantly increased.

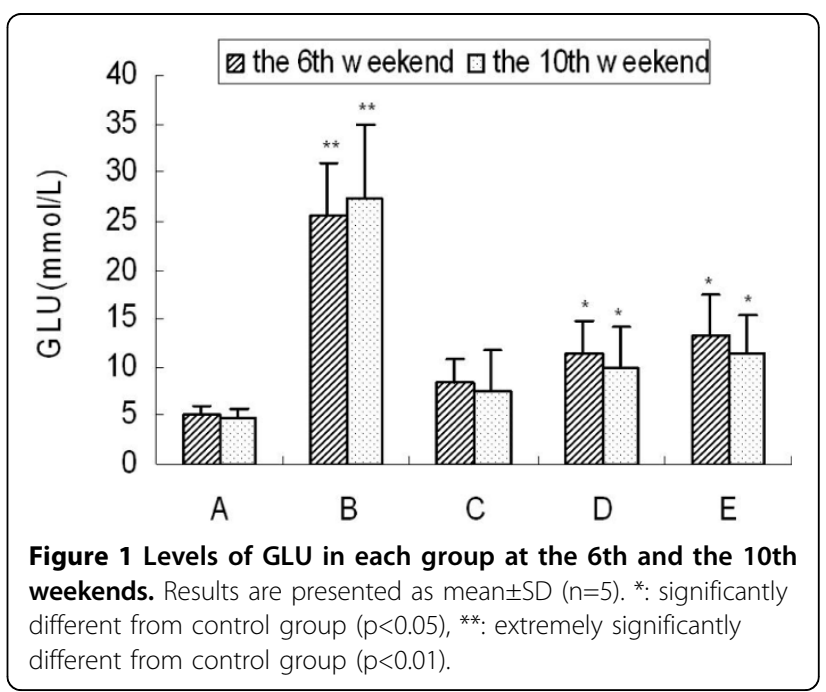




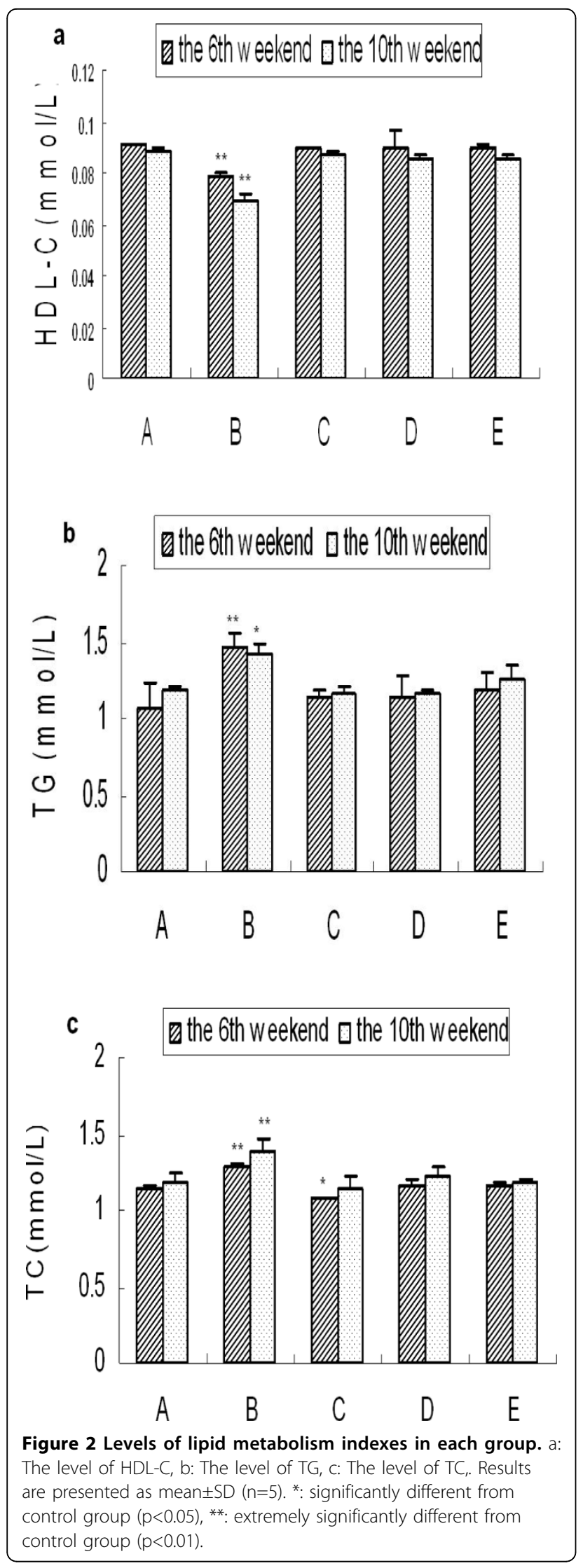

Taurine could significantly improve the indexes associated with lipid metabolism nearly to the normal levels.

\section{Analysis of kidney functional parameter}

As shown in Fig. 3, the concentrations of BUN, Scr and NAG were significantly higher in the spontaneous recovery group compared with the control group, while there were no significant differences between the taurine and the control groups. At the end of the 10th week, the concentration of NAG in the high concentration of tautine group was significantly lower than that of the control group, while the concentration of which was significantly higher than the control group.

\section{Expression of kidney basement membrane adherent protein}

As shown in Fig. 4, the expression level of LNB1mRNA in the spontaneous recovery group was extremely significantly higher than the control group $(\mathrm{P}<0.01)$. At the end of the 6th week, the expression levels in the low and medium concentration of taurine groups were significantly higher than the control group $(\mathrm{P}<0.05)$, while which in the high concentration of taurine group was significantly lower than the control group $(\mathrm{P}<0.05)$. At the 10th weekend, the expression levels in the medium and the low concentration of taurine groups were extremely significant higher than the control group $(\mathrm{P}<0.01)$, while the high concentration of taurine group had no significant differences compared with the control group.

It was shown in Fig. 5 that at the end of the 6th and the 10th weeks, the expression level of LNB1mRNA in the spontaneous recovery group was significantly higher than the control group. At the end of the 6th week, the expression level in the high concentration of taurine group was significantly lower than the control group.At the end of the 10th week, the expression level in the high dose of taurine group had no significant differences compared with the control group, meanwhile it was lower than the spontaneous recovery group at the end of the 6th and the 10th weeks.

\section{Discussion}

\section{Blood glucose level and DN}

In 1993, a report from American Diabetes Academy and the diabetes control and complications trial ( DCCT ) published in the New England Medical Journal verified that intensification therapy of insulin could keep the blood glucose at normal level and postpone the occurrence and the development of DN [12]. In addition, a perspective study in England verified that intensification therapy of insulin could obviously decrease the occurrence of type II DN [13]. These clinical researchers demonstrated the effect of high glucose in the occurrence and the development of DN. It has been reported that taurine 


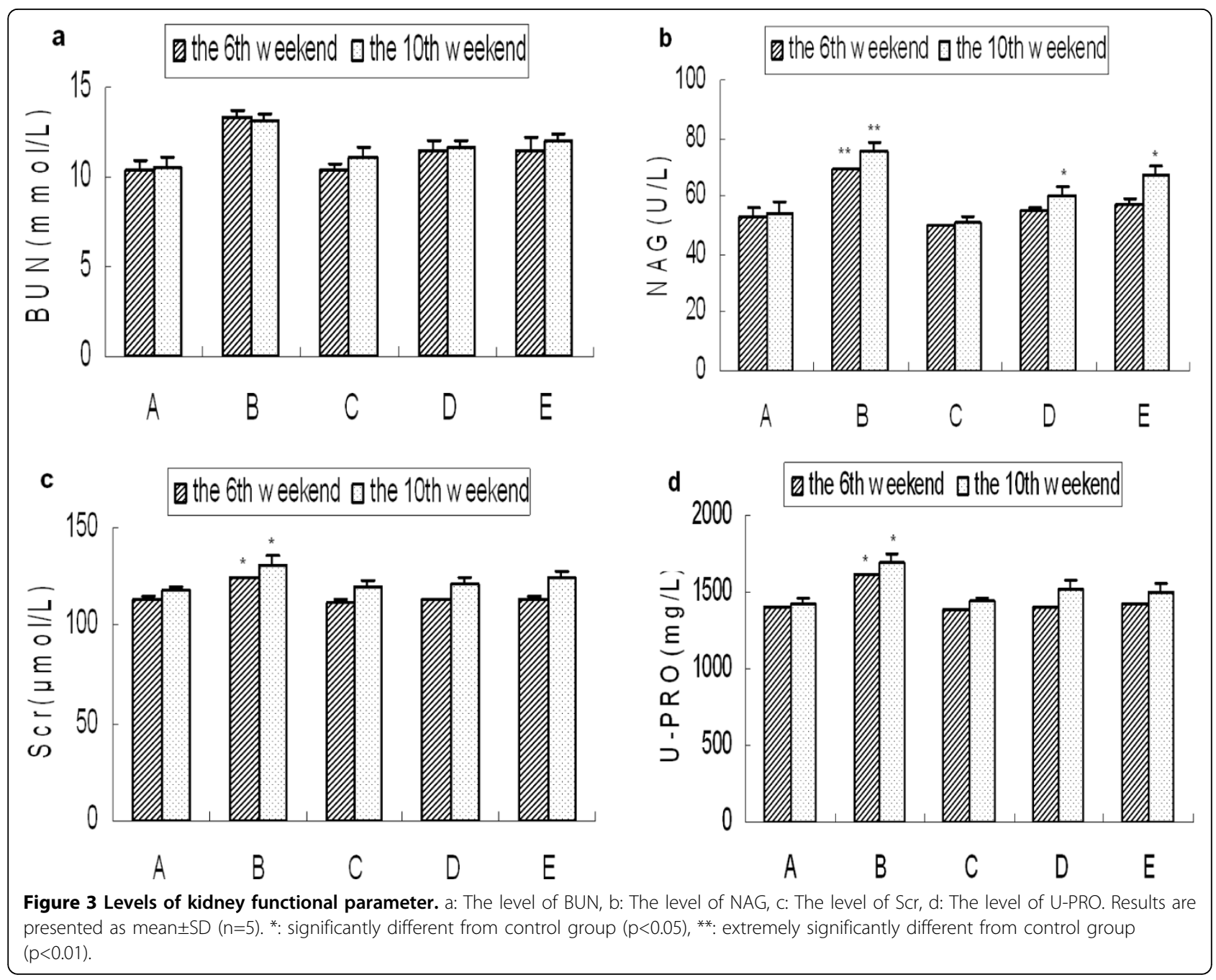

administered to STZ induced diabetic ddy or CD-1 mice could not only decrease the high blood glucose level, but also inhibit the decrease of serum insulin [14]. Harold OG et al and Donadio et al found that taurine preventively given to STZ induced insulin-dependent DM animal models could significantly decrease blood glucose, increase glucose content in skeletal and cardiac muscles, facilitate the composition and degradation of glycogen, and promote the transformation from $3 \mathrm{H}$-glucose to glycogen $[15,16]$. But $\mathrm{Ha}$ et al (1999) believed that taurine could not decrease blood glucose. This study confirmed that taurine could effectively reduce blood glucose, prevent the occurrence and development of DN, which is consistent with most reports.

\section{Lipid metabolism and DN}

Clinical research found that lipid metabolism disorder is an independent risk factor of type IIDN. It has been confirmed by animal experiment that hypercholesteremia could cause focal glomerulosclerosis. Kasiske et al. have reported that hypertriglyceridemia accelerated the occurrence of albuminuria and glomcrulus damage in obesity model rats [17]. The increase of blood is equal to the increase of urinary albumin excretion rate. The decrease of the blood fat could protect the kidney from glomerular sclerosis.

HDL-C is a protective factor against atherosclerosis. It can prevent the occurrence of renal artery atherosclerosis, reducing the probability of DN. Lin (1998) and Zhao (2005) confirmed that taurine could decrease serum TG, TC, increase HDL-C level of rats fed with high fat diet, which means that taurine could improve lipid metabolism of rats fed with high fat diet $[18,19]$. Nishimura investigated rats with genetic type IIDM and found that taurine could obviously decrease plasma TC in rats fed with high cholesterol diet. While taurine had no effect on plasma TC in rats fed with normal diet, but could significantly increase plasma HDL-C in GK rats. These results indicated that taurine had a significant effect on decreasing blood fat and promoting lipid metabolism. 


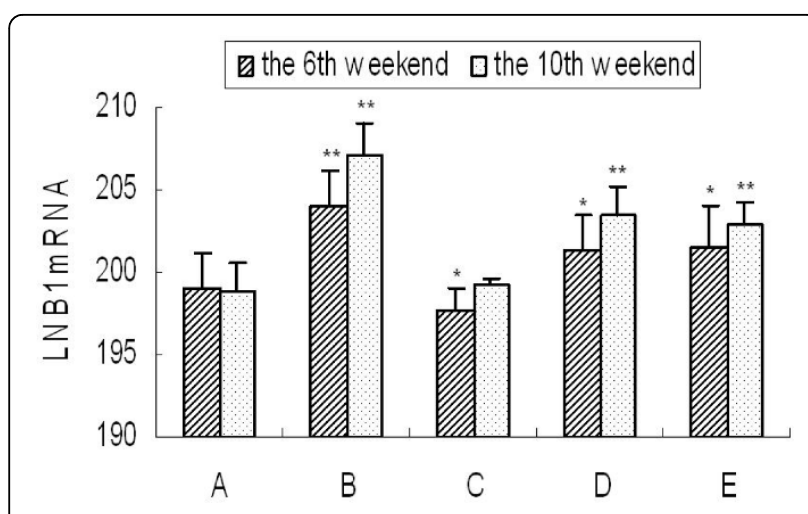

Figure 4 Levels of kidney basement membrane adherent protein expression. A: LNB1mRNA expression level of the control group At the end of the 6th and the 10th weeks, B: LNB1mRNA expression level of the spontaneous recovery group At the end of the 6th and the 10th weeks, C:LNB1mRNA expression level of high concentration of taurine group At the end of the 6th and the 10th weeks, D: LNB1mRNA expression level of the medium concentration of taurine group At the end of the 6th and the 10th weeks, E: LNB1mRNA expression level of the low concentration of taurine group At the end of the 6th and the 10th weeks. Results are presented as mean $\pm S D(n=4)$. *: significantly different from control group $(p<0.05),{ }^{* *}$ : extremely significantly different from control group $(p<0.01)$
Murakami et al administered taurine in drinking water and found that taurine could obviously decrease plasma $\mathrm{TC}$ and increase plasma HDL-C in rats [20]. This study showed that taurine could increase HDL-C, decrease TC and TG, which confirmed that taurine can reduce the probability of $\mathrm{DN}$ by effectively improving lipid metabolism.

\section{Basement membrane adherent protein expression and DN}

The main pathological changes of $\mathrm{DN}$ is the thickening of the glomerular capillary basement membrane, the proliferation of mesangial cells and the increase of mesangial matrix, the thickening of tubular basement membrane, and eventually leading to diffuse or nodular glomerulosclerosis, and tubulointerstitial interstitial fibrosis. LN which located inside the loose layer of GBM, is an important constitution of GBM and ECM. LN plays important roles in mediating the interaction between the cells and matrix, cell adhesion, migration, proliferation and differentiation. LN can cause cell adhesion and affect the selectivity of GBM charge. As a sign of kidney damage, LN is an important index for DN development [21]. Immunohistochemically an increase
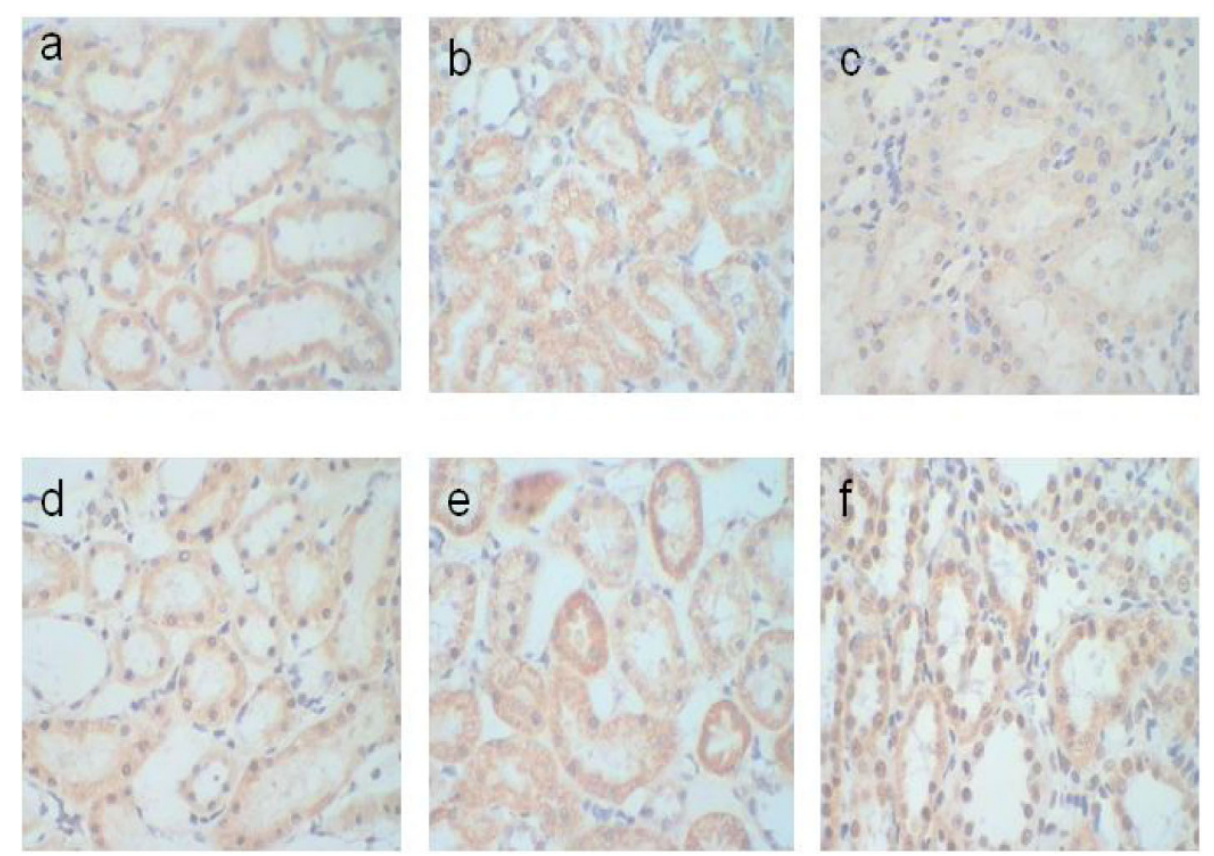

Figure 5 In situ hybridization of adherent protein expression in kidney basement membrane. The brown area was the positive expression area, enlarge 400区 under light microscope. a: LNB1mRNA expression level of the control group at the end of the $6^{\text {th }}$ week $\mathbb{b}$ : LNB1mRNA expression level of the spontaneous recovery group at the end of the $6^{\text {th }}$ week冈c: LNB1mRNA expression level of the high concentration of taurine group at the end of the $6^{\text {th }}$ week冈 $\mathrm{d}$ : LNB1mRNA expression level of the control group at the end of the $10^{\text {th }}$ week冈e区 LNB1mRNA expression level of the spontaneous recovery group at the end of the $10^{\text {th }}$ week区f: LNB1mRNA expression level of the high concentration of taurine group at the end of the $10^{\text {th }}$ week. 
of LN, collagen III and IV staining was observed in the mesangium and in the glomerular basement membrane [22]. The first laminin was isolated in 1979 from the mouse Engelbreth-Holm-Swarm (EHS) tumour [23]. $\mathrm{LN}$ is a large basement membrane-specific glycoprotein composed of three chains:A,B1,B2 [24]. Structural analysis using electron microscopy revealed $\mathrm{LN}$ as a cruciform-like structure with three short arms and one long arm [25]. The long arm consists of an $\alpha$-helical coiled coil and is the only region in which all three chains associate [26]. In fact, in the absence of collagen IV, the other major component that assembles into a scaffold, LN has been shown to be sufficient for forming basement membrane-like matrices during early development of mice embryos [27]. Immunostaining for laminin was increased in the diabetic male SD rats (200-250g) by intravenous injection of STZ in citrate buffer $(50 \mathrm{mg} / \mathrm{kg}$ ) as compared with the control group [28]. Light and electron microscopy demonstrated a moderate increase of mesangial matrix and thickening of the glomerular basement membrane in diabetic rats. Fukui et al. reported increased mRNA levels for $\alpha 1(\mathrm{IV})$ collagen, LNB1 and B2, and $\alpha 1$ (I) and $\alpha 1$ (III) collagen in diabetic rats $4 \mathrm{wk}$ after STZ before morphological thickening of basement membrane occurred [29]. LNB1 mRNA level was increased 1.7 fold in diabetic NOD mice than in agematched nondiabetic NOD mice with normal glucose tolerance [30]. In this experiment, LNB1 cDNA probes were used for in situ hybridization, which can efficiently detect the LN level in glomerular basement membrane. This study confirmed that high doses of taurine can effectively reduce the expression level of LNB1mRNA and improve the metabolism of glomerular basement membrane. However, this improvement was reduced with time, the specific mechanism of which remains to be further investigated.

\section{Conclusion}

In conclusion, taurine has some preventive effect on experimental type II DN, the mechanism of which may be due to the decreasing blood glucose, improving lipid metabolism, glomerular basement membrane metabolism, and kidney function.

\footnotetext{
List of abbreviations used

DM: diabetes mellitus; DN: diabetic nephropathy; HDL-C: high-density lipoprotein cholesterol; TG: triglyceride; TC: total cholesterol; BUN: blood urea nitrogen; Scr: proteinuria; STZ: streptozotocin; DEPC: diethyl pyrocarbonate; ECM: extracellular matrix ; CRF: chronic renal failure; LN: laminin; LNB1: laminin B1; GBM: glomerular basement membrane; FBG: fasting blood glucose; FINS: fasting insulin; ISI: insulin sensitivity index; HOMA-IR: homeoestasis model assessment -insulin resistance.
}

\section{Acknowledgements}

This article has been published as part of Journal of Biomedical Science Volume 17 Supplement 1, 2010: Proceedings of the 17th International
Meeting of Taurine. The full contents of the supplement are available online at http://www.jbiomedsci.com/supplements/17/S1.

This work was supported by the National Natural Science Foundation of China (Grant No. 30972154) and Talents Project of Liaoning Provincial Department of Education (Grant No.2009R50).

\section{Authors' contributions}

Shumei Lin carried out determination of blood glucose targets, participated in the study design and drafted the manuscript. Jiancheng Yang participated in the detection of insulin resistance, the design of the study and performed the statistical analysis. Gaofeng Wu carried out the Sampling and insulin determination. Mei Liu participated in detection of lipid metabolism. Xinhong Luan participated in detection of LNB1 in situ hybridization in kidney. Qiufeng Lv participated in rat raising. He Zhao carried out the establishment of type II diabetes model. Jianmin Hu conceived of the study, and participated in its design and coordination and helped to draft the manuscript. All authors read and approved the final manuscript.

\section{Competing interests}

The authors declare that they have no competing interests.

\section{Published: 24 August 2010}

\section{References}

1. Andersen AR, Christiansen JS, Andersen JK, Kreiner S, Deckert T: Diabetic nephropathy in type 1 (insulin-dependent) diabetes: An epidemiological study. Diabetologia 1983, 25(6):496-501.

2. Mats B, Hans JA, Goran H, Bengt EK, Johnny L: Declining Incidence of Nephropathy in Insulin-Dependent Diabetes Mellitus. N Engl J Med 1994, 330(1):15-18.

3. Barry MB, Mark EC, Dick de Z, William FK, William EM, Hans-Henrik P, Giuseppe R, Steven MS, Zhonxin Z, Shahnaz S: Effects of Losartan on Renal and Cardiovascular Outcomes in Patients with Type 2 Diabetes and Nephropathy. N Engl J Med 2001, 345(12):861-869.

4. Zirun W: Pathogenesis of diabetic nephropathy. Modem Journal of Integrated Traditional Chinese and Western Medicine 2009, 18(19):2349-2350.

5. Gaofeng W, Jiancheng $Y$, Changmian S, Xinhong $L$, Jiao S, Jianmin H: Effect of taurine on alcoholic liver disease in rats. Amino Acids 2009, 36:457-464.

6. Trachtman H, Futterweit S, Maesaka J, Ma C, Valderrama E, Fuchs A, Tarectecan A A, Rao PS, Sturman JA, Boles TH, et al: Taurine ameliorates chronic streptozocin-induced diabetic nephropathy in rats. Am J Physiol 1995, 269(3 Pt 2):F429-F438.

7. Erdem A, Gundogan NU, Usubutun A, Kilinc K, Erdem SR, Kara A, Bozkurt A: The protective effect of taurine against gentamicin-induced acute tubular necrosis in rats. Nephrol. Dial. Transplant 2000, 15(8):1175-1182.

8. Higo S, Miyata S, Jiang QY: Taurine Administration after Appearance of Proteinuria Retards Progression of Diabetic Nephropathy in Rats. Kobe J. Med. Sci 2008, 54(1):E35-E45.

9. $\mathrm{Ha} \mathrm{H}, \mathrm{Yu}$ MR, Kim KH: Melatonin and taurine reduce early glomerulopathy in diabetic rats. Free Radic Biol Med 1999, 26(4):944-950.

10. Skolnik EY, Yang Z, Makita Z, Radoff S, Kirstein M, Vlassara H: Human and rat mesangial cell receptors for glucose-modified proteins: potential role in kidney tissue remodelling and diabetic nephropathy. J Exp Med 1991, 174(4):931-939.

11. Emoto M, Nishizawa $Y$, Maekawa $K$, Hiura $Y$, Kanda $H$, Kawagishi $T$, Shoji $T$, Okuno $Y$, Morii $\mathrm{H}$ : Homeostasis model assessment as a clinical index of insulin resistance in type 2 diabetic patients treated with sulfonylureas. Diabetes care 1999, 22(5):818-822.

12. DCCT Research Group: The effect of intensive treatment of diabetes on the development and progression of long-term complications in the insulin-dependent diabetes mellitus. N Engl J Med 1993, 329:977-986.

13. UKPDS Group: Intensive blood-glucose control with sulphonylureas or insulin compared with conventional treatment and risk of complications in patients with type 2 diabetes (UKPDS 33). Lancet 1998, 352:837-853.

14. Tokunaga $\mathrm{H}$, Yoneda $\mathrm{Y}$, Kuriyama K: Protective actions of taurine against streptozotocin-induced hyperglycemia. Biochem Pharmacol 1979, 28(18):2807-2811.

15. Harold OG, Zak KS: Supplemental taurine in diabetic rats:effects on plasma glucose and triglycerides. Biochem Med Metab Biol 1990, 43(1):1-9.

16. Donadio G, Fromageot P: Influence exerted by taurine on the utilization of glucose by the rat. Bull Soc Chim Biol (Paris) 1964, 46:293-302. 
17. Kasiske BL, O'Donnel MP: The Zucker rat model of obesity, insulin resistance, hyperlipidemia and renal injury. Hypertension 1992, 19(1 Suppl):1110-1115.

18. Lin J, Kang Y: Effect of Taurine on Experimental Hyperlipidemia in Rats. Chinese Journal of Hypertension 1998, 6(1):14-16.

19. Peng $Z$, Bin $L$, Junfeng $Y$, Rongzhen $L$, Weitao $H$, Fengwen $L$ : Effect of Natural Taurine on Reducing Blood Lipids. Acta Nutrimenta Sinica 2005, 27(1):70-71.

20. Murakami S, Yamagishi I, Asami Y, Ohta Y, Toda Y, Nara Y, Yamori Y: Hypolipidemic Effect of Taurine in Stroke-Prone Spontaneously Hypertensive Rats. Pharmacology 1996, 52(5):303-313.

21. Meilun $X$, Weifang $L$, Weiqiong $W$ : The changes of the serum level of the type IV collagen as well as laminin in diabetic nephropathies and its correlated risk factors. HaiNan Med J 2007, 16(2):6-7.

22. Born J, Kraats AA, Bakker MAH, Assmann KJM, Heuvel LPWJ, Veerkamp JH, Berden JHM: Selective proteinuria in diabetic nephropathy in the rat is associated with a relative decrease in glomerular basement membrane heparan sulphate. Diabetologia 1995, 38(2):161-172.

23. Timpl R, Rohde H, Robey PG, Rennard SI, Foidart JM, Martin GR: Laminin a glycoprotein from basement membrane. The Journal of Biological Chemistry 1979, 254(10):9933-9937.

24. Sasaki M, Yamada Y: The Laminin B2 Chain Has Multidomain Structure Homologous to the B1 Chain. The Journal of Biological Chemistry 1987, 262(15):17111-17117.

25. Engel J, Odermatt E, Engel A, Madri JA, Furthmayr $\mathrm{H}$, Rohde H, Timpl R: Shapes, domain organizations and flexibility of laminin and fibronectin, two multifunctional proteins of the extracellular matrix. J. Mol. Biol 1981, 150(25):97-120.

26. Paulsson M, Deutzmann R, Timpl R, Dalzoppo D, Odermatt E, Engel J: Evidence for coiled-coil alpha-helical regions in the long arm of laminin. EMBO J 1985, 4(2):309-316.

27. Poschl E, Schlotzer-Schrehardt U, Brachvogel B, Saito K, Ninomiya Y, Mayer U: Collagen IV is essential for basement membrane stability but dispensable for initiation of its assembly during early development. Development 2004, 131(4):1619-1628.

28. Thallas-Bonke V, Lindschau C, Rizkalla B, Bach LA, Thallas-Bonke V, Lindschau C, Rizkalla B, Bach LA, Boner G, Meier M, Haller H, Cooper ME, Forbes JM: Attenuation of Extracellular Matrix Accumulation in Diabetic Nephropathy by the Advanced Glycation End Product Cross-Link Breaker ALT-711 via a Protein Kinase C- $\alpha-$ Dependent Pathway. Diabetes 2004, 53(11):2921-2930.

29. Fukui M, Nakamura T, Ebihara I, Shirato I, Tomino Y, Koide H: ECM gene expression and its modulation by insulin in diabetic rats. Diabetes 1992 41(12):1520-1527.

30. Yang CW, Hattori M, Vlassara $\mathrm{H}, \mathrm{He} \mathrm{CJ}$, Carome MA, Yamato E, Elliot $\mathrm{S}$, Striker GE, Striker L: Overexpression of transforming growth factor-beta 1 mRNA is associated with up-regulation of glomerular tenascin and laminin gene expression in nonobese diabetic mice. Journal of the American Society of Nephrology 1995, 5(8):1610-1617.

doi:10.1186/1423-0127-17-S1-S46

Cite this article as: Lin et al:: Preventive effect of taurine on

experimental type II diabetic nephropathy . Journal of Biomedical Science 2010 17(Suppl 1):S46.

\section{Submit your next manuscript to BioMed Central and take full advantage of:}

- Convenient online submission

- Thorough peer review

- No space constraints or color figure charges

- Immediate publication on acceptance

- Inclusion in PubMed, CAS, Scopus and Google Scholar

- Research which is freely available for redistribution

Submit your manuscript at www.biomedcentral.com/submit
Biomed Central 